\title{
Synthesis of Spherical Zirconia by Precipitation Between Two Water/Oil Emulsions
}

\author{
Mei-Hwa Lee, ${ }^{*}$ Clifford Y. Tai and Chung-Hsin Lu \\ Department of Chemical Engineering, National Taiwan University, Taipei 10617, Taiwan
}

(Received 3 December 1998; accepted 30 January 1999)

\begin{abstract}
Microparticles of $\mathrm{ZrO}_{2}$ are produced by using precipitation method between two emulsion solutions. First, two solutions of stable reverse emulsion (water-in-oil) are prepared and mixed to form gelled precipitates, using normal heptane as the continuous oil phase and aqueous solutions of zirconium oxyacetate and aqueous ammonia as the suspending droplets. Through a series of operations, including distillation, filtration and washing, the dried precursors are obtained. After calcining the precursors at $750^{\circ} \mathrm{C}, \mathrm{ZrO}_{2}$ powder with a tetragonal structure is obtained. Principle factors that influence the emulsion stability, which subsequently affects the morphology and particle size of $\mathrm{ZrO}_{2}$ powder, are investigated, including the type and concentration of surfactant, volume ratio of water/oil, concentration of solute in water phases, and mixing intensity and time for emulsion formation. Four kinds of anionic surfactants are put to test for emulsion stability; among them Span 40 and Span 80 are considered as suitable surfactants for producing spherical microparticles of $\mathrm{ZrO}_{2}$, which has a size range from several hundred nanometers to micrometers depending on the synthesis conditions. (C) 1999 Elsevier Science Limited. All rights reserved
\end{abstract}

Keywords: emulsions, powders-chemical preparation, $\mathrm{ZrO}_{2}$, spherical particles.

\section{Introduction}

Zirconia possesses special properties of low thermal conductivity, high mechanical strength, and high fracture toughness. Therefore, it is useful in many applications, such as structural and hightemperature ceramics. Specifications on particle size, shape, and size distribution of powder are

*To whom correspondence should be addressed. required for ceramic processing. Ceramic powder consisting of microparticles with spherical morphology and narrow size distribution are desirable, as they result in high packing density, low sintering temperature, and uniform microstructure. A variety of techniques, including hydrothermal treatment, hydrolysis of alkoxide solutions (sol-gel method), chemical precipitation, spray drying, spray roasting, spray hydrolysis, gas-phase reaction, and precipitation in emulsion, for controlling the properties of ceramic powder have been investigated. Although the sol-gel method, ${ }^{1,2}$ spray hydrolysis process, ${ }^{3}$ and emulsion technique ${ }^{4,5}$ are successful in the preparation of spherical ceramic microparticles, the raw materials (metal alkoxides) of sol-gel and spray hydrolysis processes are too expensive to use in a large-scale production. Therefore, emulsion technique is adopted to reduce the cost of producing spherical microparticles.

Recently, a series of reports revealed the reverse emulsion technique for preparing ceramic particles with spherical morphology, such as $\mathrm{Y}_{2} \mathrm{O}_{3}, \mathrm{Al}_{2} \mathrm{O}_{3}$, $\mathrm{TiO}_{2}$, and $\mathrm{ZrO}_{2}$. Spherical $\mathrm{Y}_{2} \mathrm{O}_{3}$ particles were prepared by using either an emulsion precipitation method $^{6,7}$ or an emulsion evaporation method. ${ }^{8,9}$ Sarikaya and Akine ${ }^{10}$ prepared spherical hollow $\mathrm{Al}_{2} \mathrm{O}_{3}$ particles from the stable w/o-type emulsion by evaporation. $\mathrm{TiO}_{2}$ particles, with the size distribution in the range of $0 \cdot 1 \sim 2 \mu \mathrm{m}$, were prepared by using an emulsion precipitation method, ${ }^{11}$ which was also used by Shyu and Cambria ${ }^{12}$ to prepare $30 \sim 80 \mu \mathrm{m} \mathrm{ZrO}_{2}$ particles in solid or hollow state with spherical morphology. According to the work of Kanai et al. ${ }^{13}$ the optimum conditions for preparing $\mathrm{ZrO}_{2} \cdot \mathrm{Y}_{2} \mathrm{O}_{3}$ spherical particles in the sol-emulsion-gel method were determined as follows: $50 \mathrm{ml}$ heptane, $0.2 \mathrm{~g}$ Span $80,0.5 \mathrm{ml}$ water containing $3.75 \times 10^{-4}$ mole $\mathrm{ZrOCl}_{2}$. Under the optimum conditions they obtained particles with an average diameter between 0.2 and $0.3 \mu \mathrm{m}$. Using the sol-emulsion-gel method, weakly agglomerated $\mathrm{ZrO}_{2}$ of spherical clusters, which 
comprised of $4 \sim 10 \mathrm{~nm}$ particles, were produced by Sangeeta et al. ${ }^{14}$ Following the same technique, Gao et al. ${ }^{15}$ prepared Y-TZP powder with an average size of $14 \mathrm{~nm}$, which were weakly agglomerated into polyhedral or spherical shape. They ${ }^{14,15}$ chose $\mathrm{ZrO}\left(\mathrm{NO}_{3}\right)_{2} \cdot n \mathrm{H}_{2} \mathrm{O}$ (zirconyl nitrate) as the raw material instead of $\mathrm{ZrOCl}_{2} \cdot n \mathrm{H}_{2} \mathrm{O}$, because they thought the nitrogen-containing compounds lead to easier and cleaner burnout as compared with chloride-containing compounds. Kanai et al. ${ }^{13}$ Sangeeta et al. ${ }^{14}$ and Gao et al. ${ }^{15}$ used ammonia gas bubbling through the emulsion solution, which contained $\mathrm{Zr}^{2+}$ aqueous droplets, to obtain gelled precipitates and then agglomerated $\mathrm{ZrO}_{2}$ particles were obtained.

In the process of producing ceramic powder in the reverse emulsion, a surfactant must be added into the mixture of oil and water to lower the interfacial tension between the oil/water phase. When the HLB (hydrophile-lipophile balance) value of surfactant ranges between 3 and 7 , a water-in-oil emulsion is obtained. ${ }^{16,17}$ In this work, different types of surfactant, including Span 40, Span 80, Span 85, and Arlacel 83, were used to examine the emulsion stability. Then, the twoemulsion technique, i.e. precipitation by contact between two emulsion solutions, was employed to prepare spherical zirconia microparticles. Two w/o emulsions, one of aqueous zirconium oxyacetate in heptane and the other one of aqueous ammonia in heptane, with the same w/o ratio and surfactant weight were prepared separately. The two stable solutions of w/o emulsion were mixed to form slurry containing gelled precipitates. After removal of water, the slurry went through a series of operations to recover the precipitates. Then the particle size dis- tribution and surface area were measured and the surface structure and particle morphology were examined. The principal factors, including the concentration of zirconium ion, the mixing intensity and time during emulsion formation, the volume ratio of $\mathrm{w} / \mathrm{o}$, and the concentration of surfactant that influence the stability of emulsion and the properties of the $\mathrm{ZrO}_{2}$ particles were investigated when Span 40 or Span 80 were used as the surfactant.

\section{The Two-Emulsion Technique}

To produce spherical ceramic powder, ammonia gas is introduced by bubbling through the emulsion solution containing $\mathrm{Zr}^{2+}$ aqueous droplets as reported by Kanai et al. ${ }^{13}$ and Sangeeta et al. ${ }^{14}$ The ammonia gas dissolves first and then diffuses through the oil phase to reach the micelles where the hydrolysis of the metal-containing compound takes place to form the product particles. Since the ammonia bubbles are not evenly distributed in the emulsion solution, the concentration of the absorbed ammonia is not uniform in the oil phase. As a result, the size distribution of the produced particles might be wider. To overcome this problem, the two-emulsion technique is employed.

The basic idea of the two-emulsion technique is illustrated in Fig. 1. Two reverse-emulsion solutions, in which zirconium oxyacetate aqueous droplets or aqueous ammonia droplets is suspending in the oil phase by adding a surfactant, are prepared separately and mixed together with agitation. The contact between zirconium oxyacetate and ammonia can be achieved by the diffusion of ammonia through oil phase as route 1 , or by the

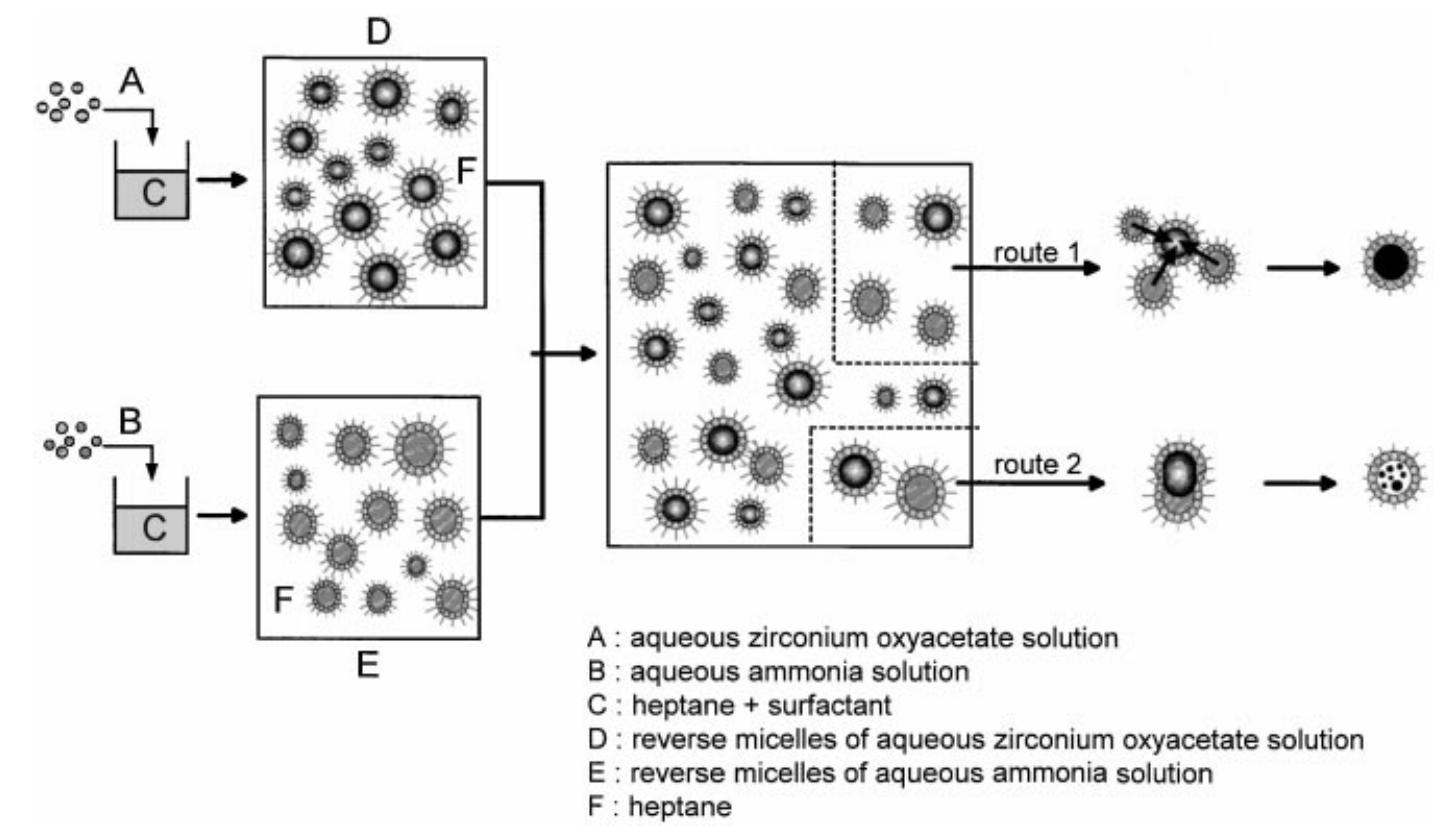

Fig. 1. The possible mechanisms of particle formation in the precipitation method between two w/o emulsions. 
coalescence of different types of droplets, such as route 2 . The emulsion droplets serve as microreactors where nucleation and crystal growth occur. The ammonia concentration in the oil phase is more uniform regardless of the contact mechanism as compared with the bubbling technique. Thus, the size, size distribution, and shape of produced particles, which are related to the size of emulsion droplets, can be controlled. Because the diffusion rate of ammonia is slow for route 1 , the supersaturation generated in the droplet is mild and the $\mathrm{ZrO}_{2}$ particles may grow to almost the same size as emulsion droplets. On the other hand, the supersaturation generated in the droplets is high due to the coalescence of different types of droplets as route 2 , there will be more numbers of crystal with smaller size. If there are more than three droplets involved in the coalescence process, it is possible to produce particles with the size being larger than the droplets.

\section{Experimental Procedure}

The flow chart for preparing zirconia powder in the reverse emulsions is shown in Fig. 2. The first step was to prepare two solutions by mixing $300 \mathrm{ml}$ normal heptane (L.C. Grade; ALPS) and a certain amount of surfactant in a $500 \mathrm{ml}$ beaker with a magnetic stirrer at ambient temperature. After the surfactant was completely dissolved in the oil phase, two aqueous solutions of equal volume, one containing aqueous ammonia (28\%; Nacalai Tesque) and the other zirconium oxyacetate (Nacalai Tesque), were added to the beakers separately. The mixtures were then subjected to ultrasonic agitation

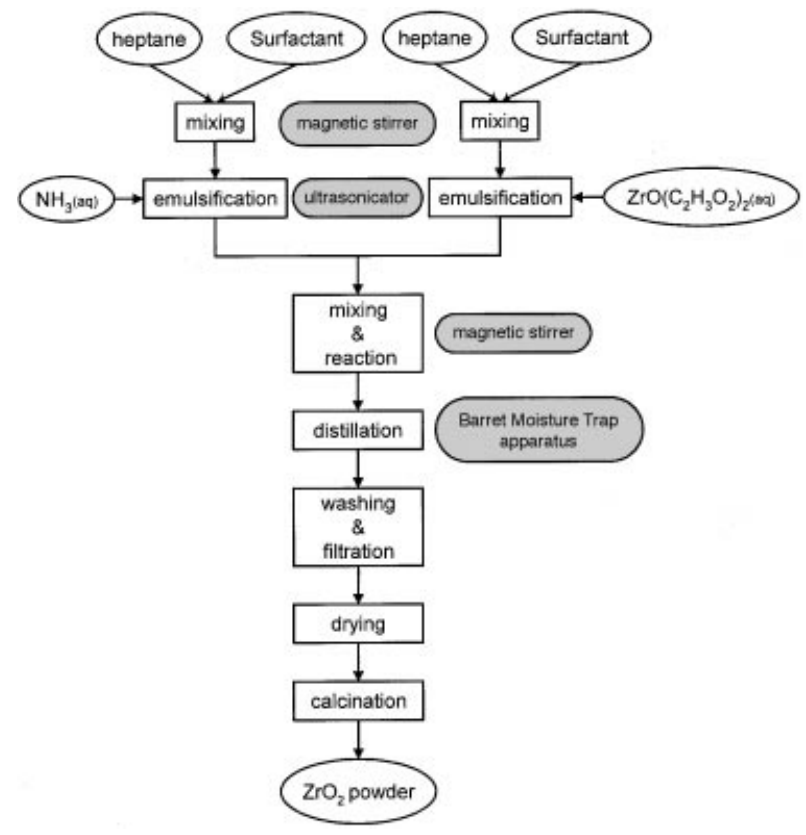

Fig. 2. Flowchart for preparing $\mathrm{ZrO}_{2}$ powder.
(Misonix, Sonicator XL2020) for several minutes and the temperature raised to $38 \sim 40^{\circ} \mathrm{C}$. Once the stable emulsions were formed, the size distribution of water droplet in the emulsion solutions was determined by a sound wave analyzer (PEN KEM, DT-1200). Four anionic surfactants have been tested for the preparation of stable emulsion. Then, the two stable emulsions were mixed and stirred with a magnetic stirrer under room temperature for $30 \mathrm{~min}$ to form gelled particles. The resultant slurry was distilled at $118 \sim 130^{\circ} \mathrm{C}$ for about $3 \mathrm{~h}$, using a 'Barret Moisiture Trap apparatus' to remove the unreacted water and most of the heptane. The apparatus of 'Barret Moisiture Trap', which is a modified 'Dean Stark Moisiture Trap', ${ }^{13}$ is illustrated in Fig. 3. Then the precipitates of $\mathrm{ZrO}_{2}$ precursor were filtered and washed with ethyl alcohol $(99.5 \mathrm{vol} \%)$ or acetone and repeated with deionized water to remove the residual surfactant and ions, then dried at room temperature for $24 \mathrm{~h}$. Finally, white $\mathrm{ZrO}_{2}$ powder was obtained by calcining at $750^{\circ} \mathrm{C}$ for $2 \mathrm{~h}$.

The sonicator used to prepare emulsion solutions contains four components: power output, $20 \mathrm{kHz}$ convertor, tapped horn, and flat tip. The diameters of horn tape and flat tip were chosen by the volume to be processed and intensity required. In the experiment, two tapped horns, titanium 200 standard and 305 high intensity, were used and the differences between the two horn types are list in Table 1. The differences between the two tapped horns are the processing volume and the power range. The processing volumes are 25 500 and

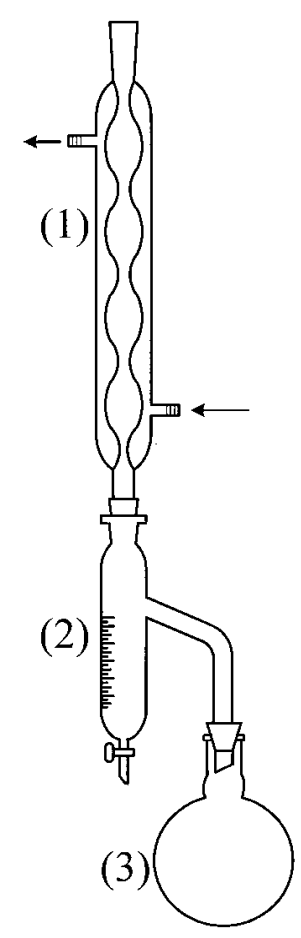

Fig. 3. Distillation apparatus: (1) condenser (2) barret moisture trap; (3) round-bottom flask. 
Table 1. Specifications of the two horn types, standard and high intensity

\begin{tabular}{lcc}
\hline & $\begin{array}{c}\text { Standard } \\
\text { horn }\end{array}$ & $\begin{array}{c}\text { High intensity } \\
\text { horn }\end{array}$ \\
\hline Part no. & 200 & 305 \\
Processing volume $(\mathrm{ml})$ & $10 \sim 250$ & $25 \sim 500$ \\
Tip diameter $(\mathrm{mm})$ & $12 \cdot 7$ & $19 \cdot 1$ \\
Amplitude $(\mu \mathrm{m})$ & 120 & 120 \\
Power $(\mathrm{W})$ & $0 \sim 165$ & $0 \sim 220$ \\
\hline
\end{tabular}

$10 \sim 250 \mathrm{ml}$ for the high intensity and low intensity horn, respectively, and the power ranges are $0 \sim 220$ and $0 \sim 165 \mathrm{~W}$ for the high intensity and low intensity horn, respectively.

Characteristics of the precursor and calcined zirconia powder were analyzed: the crystalline phase identified by an X-ray diffractometer (Mac Science MXP-3 TXT-7266), the particle size distribution measured by a static light scattering analyzer (Coulter, LS 230), the surface area determined by a BET analyzer (Micromeritics ASAP 2010), and the surface structure and particle morphology examined by a scanning electron microscope (Hitachi, S-800).

\section{Results and Discussion}

\subsection{Characteristics of emulsion}

There are many factors, including type and concentration of surfactant, concentration of aqueous phase, volume ratio of water to oil phase, and mixing intensity and time of emulsion formation, that affect the characteristics of emulsion, which would subsequently influence the properties of $\mathrm{ZrO}_{2}$ powder. Among the factors investigated in this study the most important one is the type of surfactant. The characteristics of emulsion under consideration are the stability and droplets size distribution.

\subsubsection{Emulsion stability}

Four anionic surfactants purchased from Sigma Company, Span 85 (Sorbitan Trioleate, HLB $=1 \cdot 8$ ), Arlacel 83 (Sorbitan Sesquioleate, HLB $=3 \cdot 7$ ), Span 80 (Sorbitan Monooleate, HLB $=4 \cdot 3$ ), and Span 40 (Sorbitan Monopalmitate, HLB $=6 \cdot 7$ ), were put to test for the emulsion stability, which are listed in Table 2 depending on the surfactant type, $\mathrm{Zr}^{2+}$ concentration, and volume ratio of w/o. Other variables, such as ammonia concentration and surfactant weight, are kept constant because they are less significant in a certain range. It should be noted that the mixing time is 3 min using the standard tapped horn; any mixing time below $2 \mathrm{~min}$ does not produce emulsion solutions. If Span 85 is used as the surfactant, the emulsions are unstable for all cases. Using Arlacel 83, the emulsions are unstable at high ratio of w/o $(5 / 100$ and $2 / 100)$ or at high concentration of $\mathrm{ZrO}(\mathrm{Ac})_{2}(3 \mathrm{M})$, and stable over $12 \mathrm{~h}$ at low w/o ratio $(1 / 100)$ and low $\mathrm{ZrO}(\mathrm{Ac})_{2}$ concentration $(1$ and $2 \mathrm{M})$. Span 80 is a more suitable surfactant than Span 85 and Arlacel 83 , since the emulsions are stable over $12 \mathrm{~h}$ at $\mathrm{w} / \mathrm{o}$ ratio of $1 / 100$ regardless of $\mathrm{ZrO}(\mathrm{Ac})_{2}$ concentration (from 0.5 to $3 \mathrm{M}$ ). However, when the volume ratio of w/o becomes higher $(2 / 100$ and $5 / 100)$, the

Table 2. Stability of the emulsions using various types of surfactant ${ }^{a}$

\begin{tabular}{|c|c|c|c|}
\hline Surfactant & $\begin{array}{l}\text { Concentration of } \\
\operatorname{ZrO}(A c)_{2(a q)}\end{array}$ & $\begin{array}{c}\text { Volume ratio } \\
\text { of } w / o\end{array}$ & Stability of emulsion \\
\hline \multirow[t]{5}{*}{ Span $85(\mathrm{HLB}=1 \cdot 8)$} & $1 \mathrm{M}$ & $5 / 100$ & Unstable, phases separated quickly \\
\hline & $1 \mathrm{M}$ & $2 / 100$ & Unstable, phases separated quickly \\
\hline & $1 \mathrm{M}$ & $1 / 100$ & Unstable, phases separated in $3 \sim 4 \mathrm{~min}$ \\
\hline & $2 \mathrm{M}$ & $1 / 100$ & Unstable, phases separated in $3 \sim 4$ min \\
\hline & $3 \mathrm{M}$ & $1 / 100$ & Unstable, phases separated in $3 \sim 4 \mathrm{~min}$ \\
\hline \multirow[t]{5}{*}{ Arlacel $83(\mathrm{HLB}=3 \cdot 7)$} & $1 \mathrm{M}$ & $5 / 100$ & Unstable, phases separated in $15 \mathrm{~min}$ \\
\hline & $1 \mathrm{M}$ & $2 / 100$ & Unstable, phases separated in $15 \mathrm{~min}$ \\
\hline & $1 \mathrm{M}$ & $1 / 100$ & Stable over $12 \mathrm{~h}$ \\
\hline & $2 \mathrm{M}$ & $1 / 100$ & Stable over $12 \mathrm{~h}$ \\
\hline & $3 \mathrm{M}$ & $1 / 100$ & Unstable, phases separated in $30 \mathrm{~min}$ \\
\hline \multirow[t]{6}{*}{ Span80 $($ HLB = 4·3) } & $1 \mathrm{M}$ & $5 / 100$ & Unstable, phases separated in $15 \mathrm{~min}$ \\
\hline & $1 \mathrm{M}$ & $2 / 100$ & Unstable, phases separated in $15 \mathrm{~min}$ \\
\hline & $0 \cdot 5 \mathrm{M}$ & $1 / 100$ & Stable over $12 \mathrm{~h}$ \\
\hline & $1 \mathrm{M}$ & $1 / 100$ & Stable over $12 \mathrm{~h}$ \\
\hline & $2 \mathrm{M}$ & $1 / 100$ & Stable over $12 \mathrm{~h}$ \\
\hline & $3 \mathrm{M}$ & $1 / 100$ & Stable over $12 \mathrm{~h}$ \\
\hline \multirow[t]{6}{*}{ Span $40($ HLB = 6.7) } & $1 \mathrm{M}$ & $5 / 100$ & Unstable, phases separated in $10 \mathrm{~min}$ \\
\hline & $1 \mathrm{M}$ & $2 / 100$ & Stable over $12 \mathrm{~h}$ \\
\hline & $0.5 \mathrm{M}$ & $1 / 100$ & Stable over $12 \mathrm{~h}$ \\
\hline & $1 \mathrm{M}$ & $1 / 100$ & Stable over $12 \mathrm{~h}$ \\
\hline & $2 \mathrm{M}$ & $1 / 100$ & Stable over $12 \mathrm{~h}$ \\
\hline & $3 \mathrm{M}$ & $1 / 100$ & Stable over $12 \mathrm{~h}$ \\
\hline
\end{tabular}

aperation conditions chosen: $300 \mathrm{ml}$ heptane, surfactant/oil ratio 0.4 (1.2 g surfactant $/ 300 \mathrm{ml}$ heptane), concentration of aqueous $\mathrm{NH}_{3}$ solution $14 \mathrm{M}$, ultrasonic mixing intensity $165 \mathrm{~W}$ using standard tapped horn, and mixing time $3 \mathrm{~min}$. 
emulsions are unstable at $\mathrm{Zr}^{2+}$ concentration of $1 \mathrm{M}$. The most stable emulsions are prepared by using Span 40. Besides the w/o ratio of $1 / 100$, the emulsion also stable at $\mathrm{w} / \mathrm{o}$ ratio of $2 / 100$ and $\mathrm{ZrO}(\mathrm{Ac})_{2}$ concentration of $1 \mathrm{M}$. The HLB values of Span 40 and Span 80 are within the range of the optimum HLB value, 3 7, for stable reverse emulsions. ${ }^{16,17}$

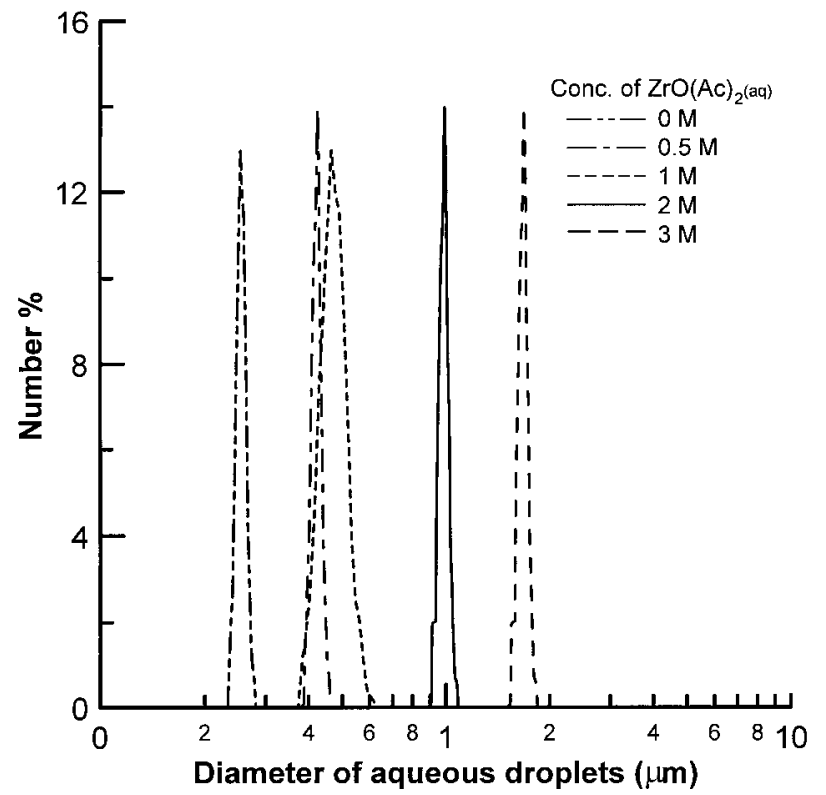

Fig. 4. The effect of $\mathrm{Zr}^{2+}$ concentration on the size distribution of aqueous droplets using Span 80 as surfactant and w/o volume ratio of $1 / 100$. The other operating conditions are the same as those in Table 2.

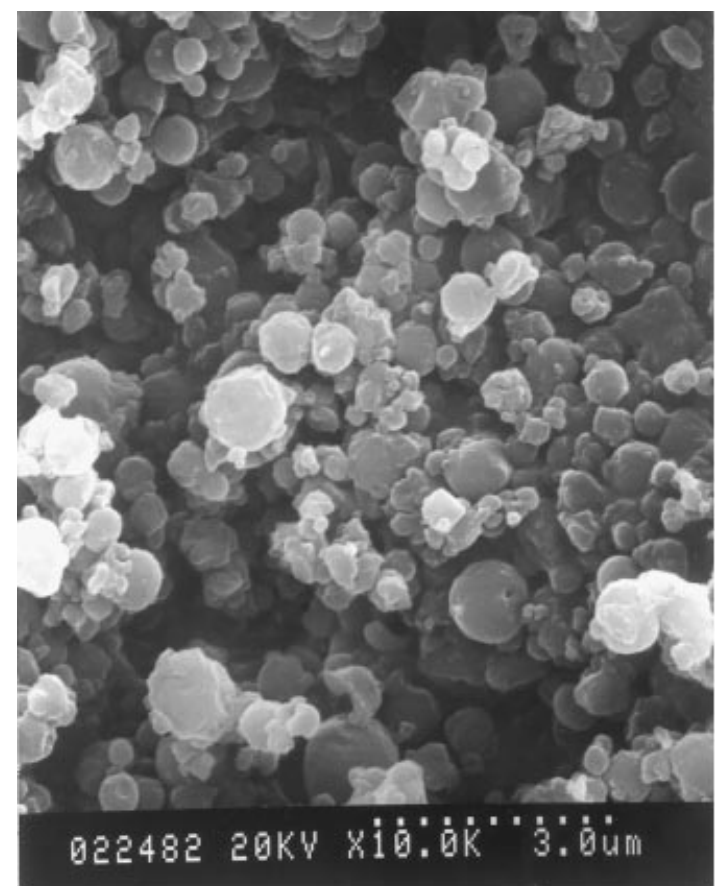

(a)

\subsubsection{Droplet size distribution of stable emulsion}

The size of water-phase droplets in emulsion is one of the important characteristics of emulsion because it would influence the size of the produced particles. To study the effect of $\mathrm{Zr}^{2+}$ concentration on the droplet size, the mixing time was set at $3 \mathrm{~min}$ using the standard horn of $165 \mathrm{~W}$ and the reverse emulsions so obtained are stable for more than $12 \mathrm{~h}$. The size distributions of the water-phase droplets at various $\mathrm{Zr}^{2+}$ concentration are shown in

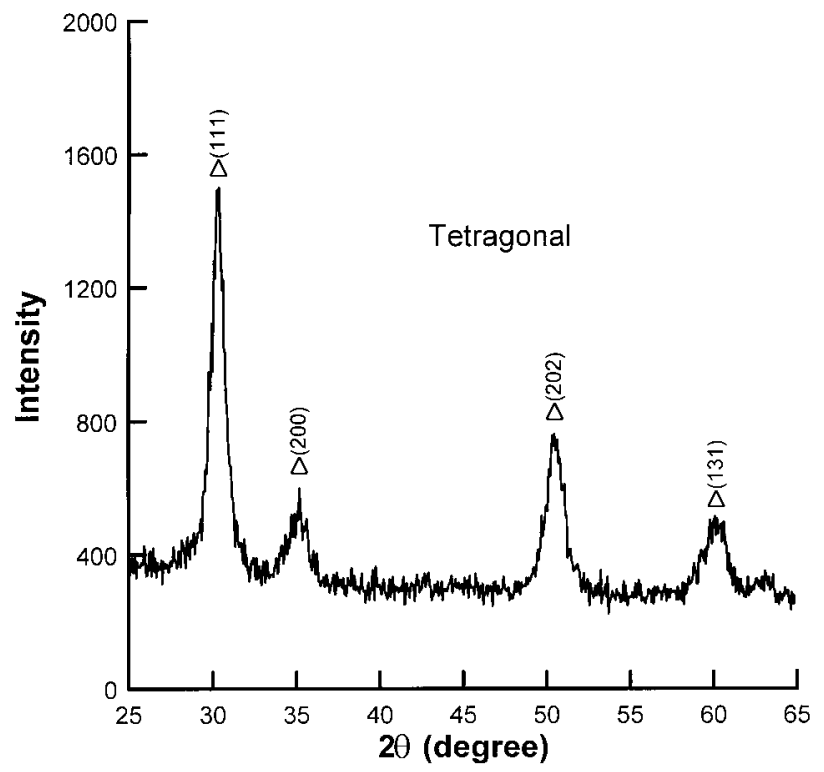

Fig. 6. X-ray diffraction pattern of $\mathrm{ZrO}_{2}$ ultra particles calcined at $750^{\circ} \mathrm{C}$ for $2 \mathrm{~h}$. The operating conditions are the same as those in Fig. 5. (Ref: JCPDS card $\sharp 17-923$ ).

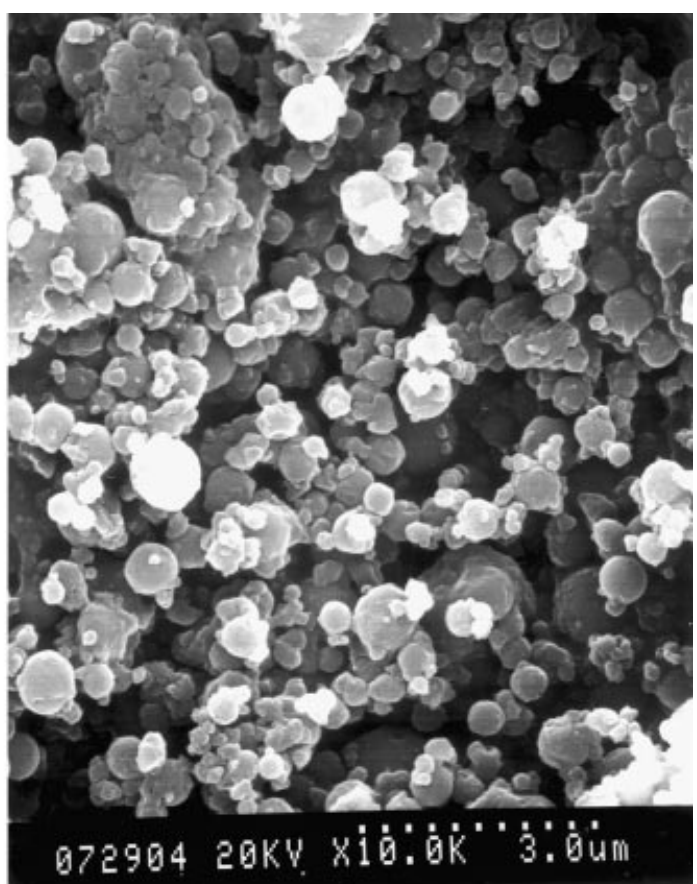

(b)

Fig. 5. Scanning electron micrographs of (a) precursors and (b) $\mathrm{ZrO}_{2}$ powder for the $\mathrm{Zr}^{2+}$ concentration of $0.75 \mathrm{M}$. The other operation conditions are the same as those in Fig. 4. 
Fig. 4. It appears that the size of the water-phase droplets is quite uniform for all $\mathrm{Zr}^{2+}$ concentrations from 0 to $3 \mathrm{M}$. The size distribution curve of droplets shifts to smaller size when the $\mathrm{Zr}^{2+}$ concentration decreases. Submicron droplets can be obtained when $\mathrm{Zr}^{2+}$ concentrations are less than $2 \mathrm{M}$. According to these results, submicron $\mathrm{ZrO}_{2}$ particles might be obtained since the submicron droplets serve as microreactors for producing particles in this two-emulsion technique.

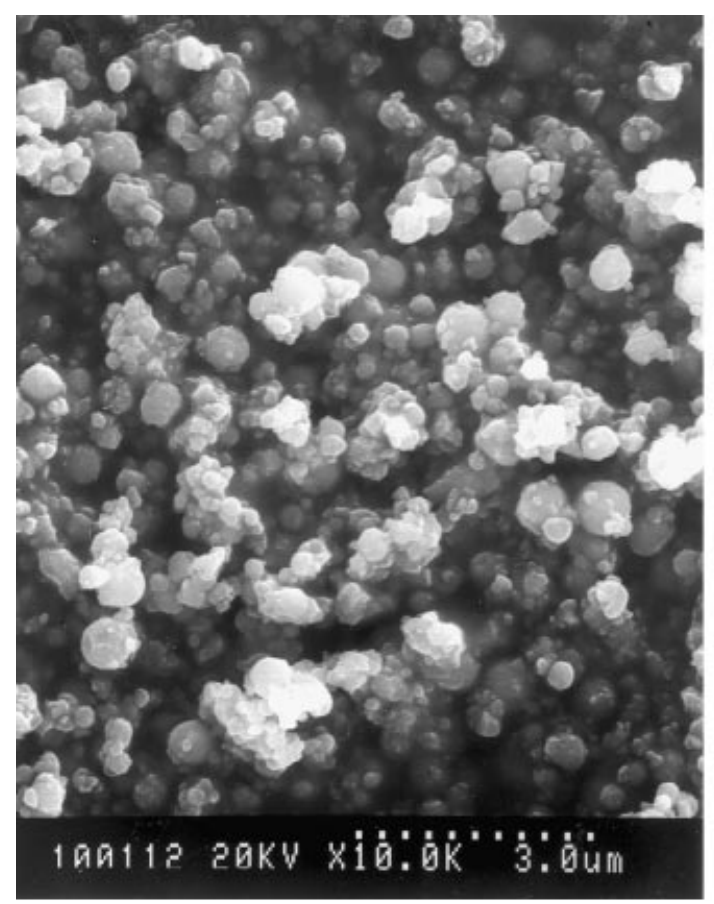

(a)

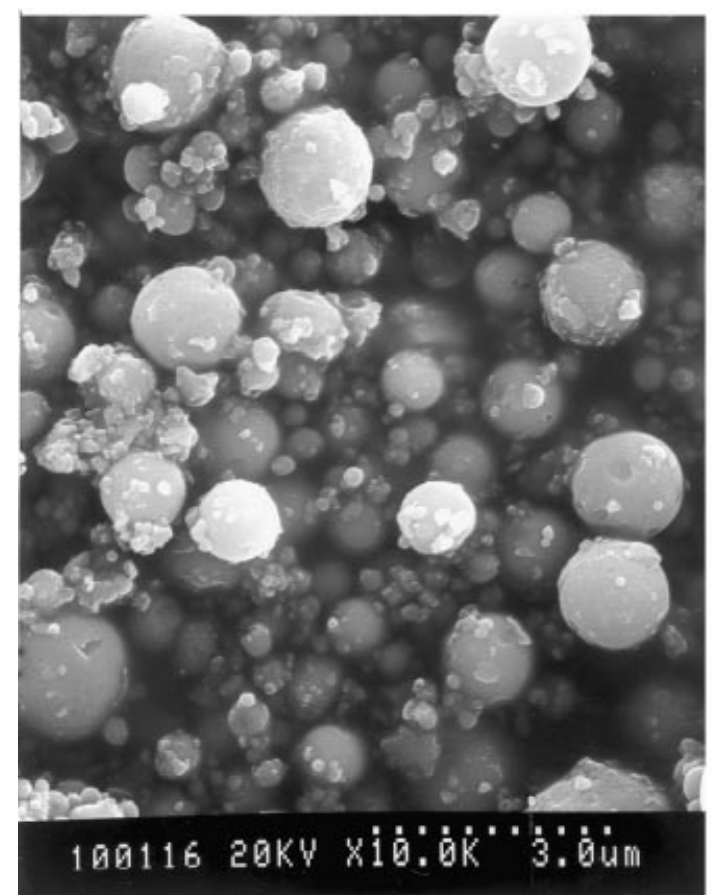

(c)

\subsection{Effects of operating variables when using Span 80 as surfactant}

Because there are many factors that influence the characteristics of the $\mathrm{ZrO}_{2}$ product crystals, we first chose the following reference conditions to perform the experiment, which are based on the optimum conditions of the work by Kannai et al. ${ }^{13}$ : volume ratio of $\mathrm{w} / \mathrm{O}=1 / 100(3 \mathrm{ml}$ water $/ 300 \mathrm{ml}$ heptane), surfactant weight $/$ oil volume $=0.4$ (1.2 g Span 80/300 $\mathrm{ml}$ heptane), $\mathrm{ZrO}\left(\mathrm{C}_{2} \mathrm{H}_{3} \mathrm{O}_{2}\right)_{2}$

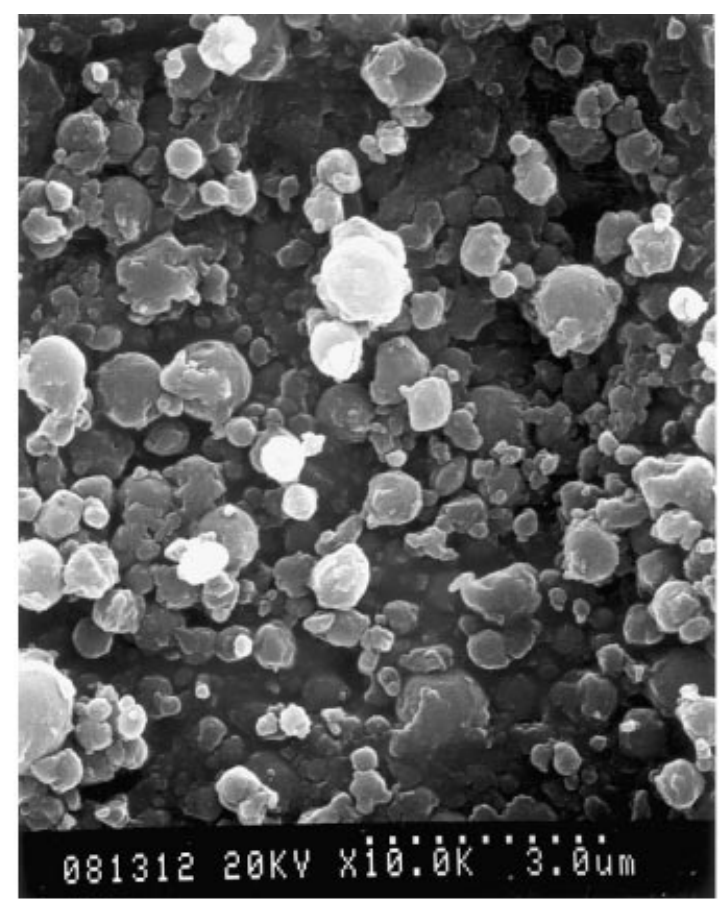

(b)

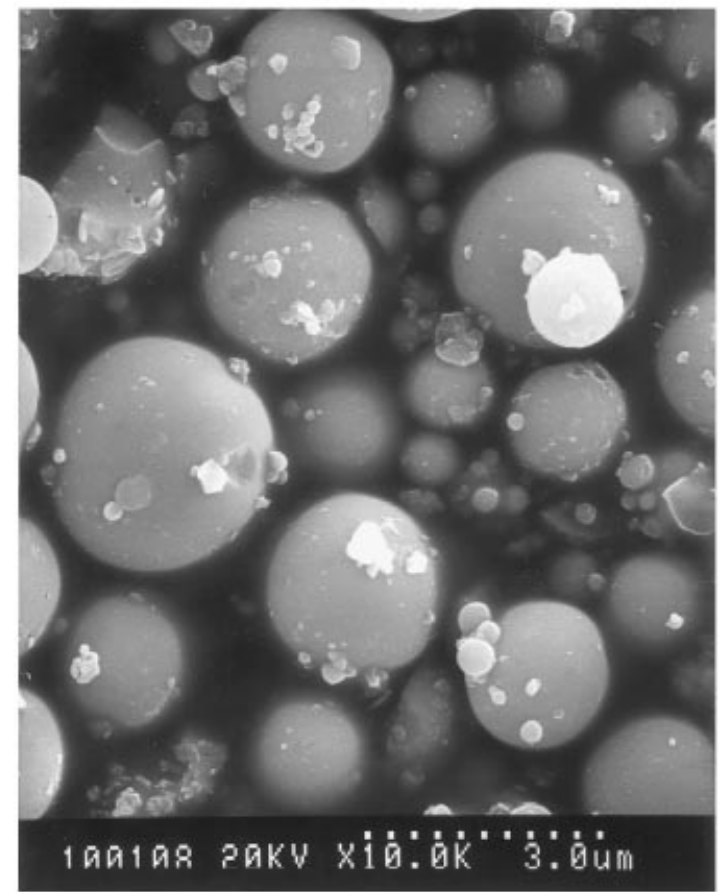

(d)

Fig. 7. Scanning electron micrographs of $\mathrm{ZrO}_{2}$ powder for various concentration of aqueous $\mathrm{ZrO}\left(\mathrm{C}_{2} \mathrm{H}_{3} \mathrm{O}_{2}\right)_{2}$ (a) $0 \cdot 5 \mathrm{M}$, (b) $1 \mathrm{M}$, (c) $2 \mathrm{M}$, (d) $3 \mathrm{M}$. The other operating conditions are the same as those in Fig. 4. 


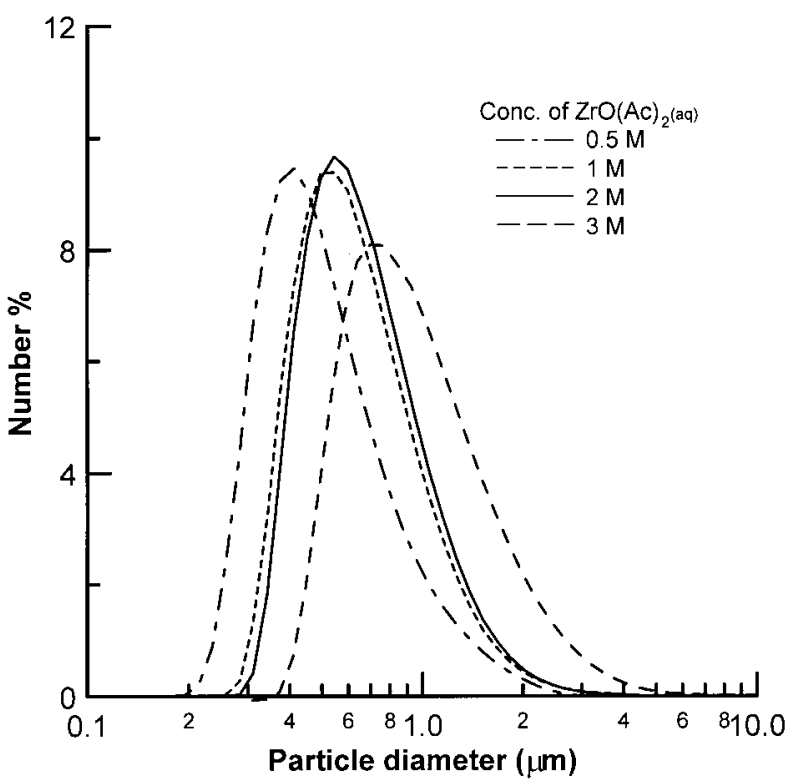

Fig. 8. Effect of $\mathrm{ZrO}\left(\mathrm{C}_{2} \mathrm{H}_{3} \mathrm{O}_{2}\right)_{2}$ concentration on the particle size distribution of the $\mathrm{ZrO}_{2}$. The operation conditions are the same as those in Fig. 4.

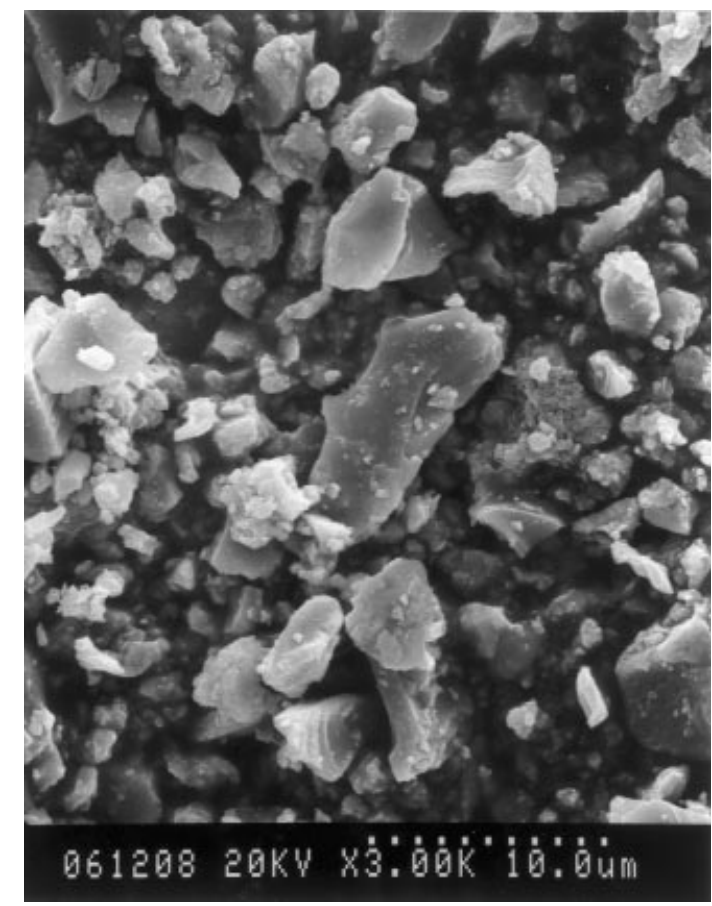

Fig. 9. Scanning electron micrograph of $\mathrm{ZrO}_{2}$ powder for the $\mathrm{w} / \mathrm{o}$ volume ratio $5 / 100$. The other conditions are the same as those in Fig. 4.

concentration $=0.75 \mathrm{M}$, and ammonia concentration $=14 \mathrm{M}$. Then the effects of each factor were investigated while keeping others constant. The resultant emulsion solutions prepared by using the above-mentioned conditions were stable for over $12 \mathrm{~h}$ when the agitation time was 3 min using the standard horn at $165 \mathrm{~W}$. The produced precursors and calcined $\mathrm{ZrO}_{2}$ particles are shown in Figs 5(a) and (b) respectively. It appears that the calcined zirconia particles are smaller than the precursors, presuming that the precursor, $\mathrm{Zr}(\mathrm{OH})_{x}\left(\mathrm{CH}_{3} \mathrm{COO}\right)_{3-x}$ where $x$ varies from 0.3 to

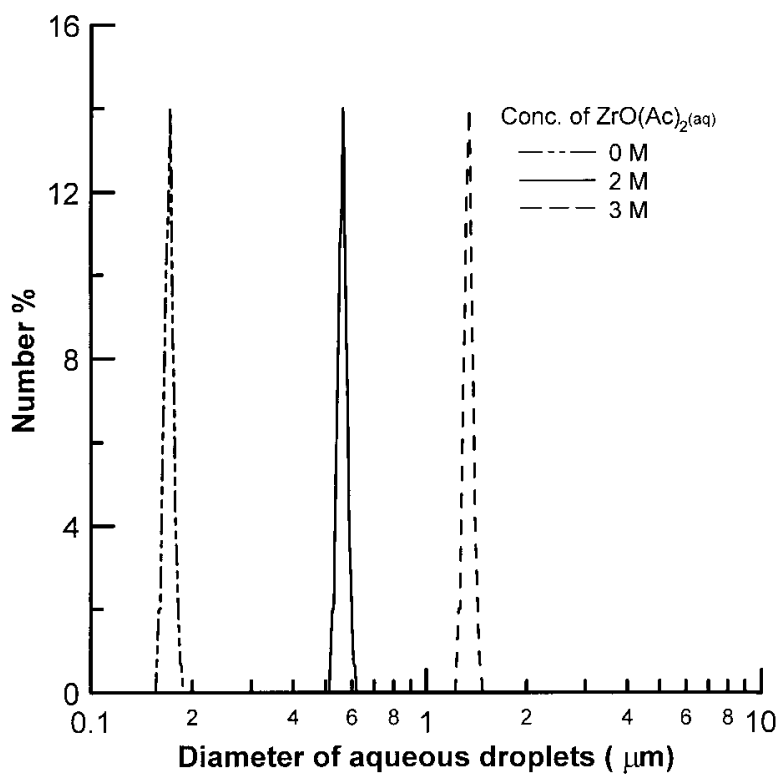

Fig. 10. The effect of $\mathrm{Zr}^{2+}$ concentration on the size distribution of aqueous droplets using high intensity tapped horn of $220 \mathrm{~W}$. The other conditions are the same as those in Fig. 4

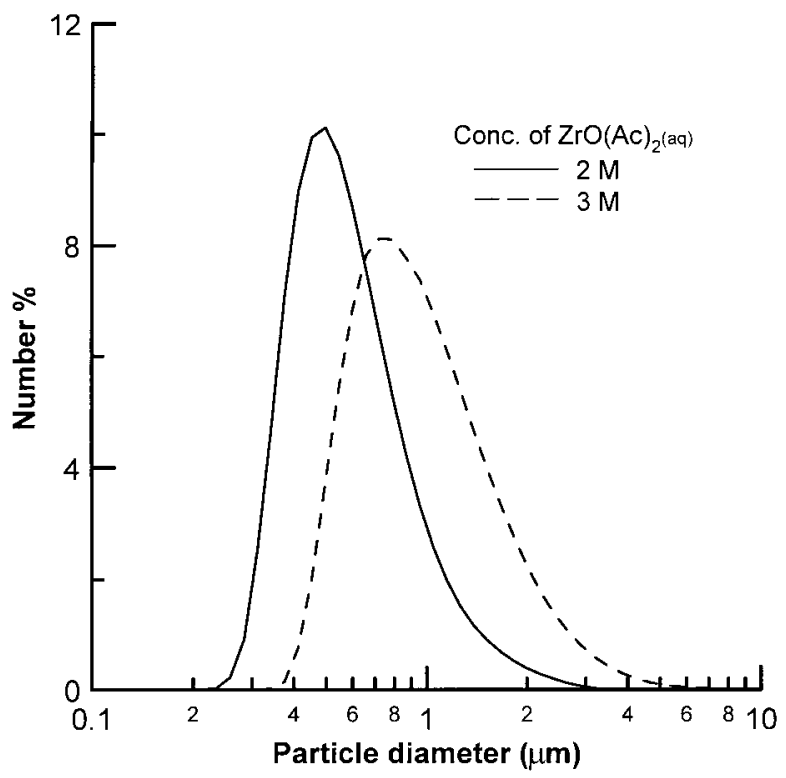

Fig. 11. Effect of $\mathrm{ZrO}\left(\mathrm{C}_{2} \mathrm{H}_{3} \mathrm{O}_{2}\right)_{2}$ concentration on the particle size distribution of the $\mathrm{ZrO}_{2}$. The operation conditions are the same as those in Fig. 10.

$3,{ }^{12}$ is reduced to $\mathrm{ZrO}_{2}$ in the calcination stage. The zirconia particles are spherulite with a size distribution between 0.1 and $1.0 \mu \mathrm{m}$. Comparing the SEM photographs of precursors and $\mathrm{ZrO}_{2}$ powder, it is found that a small portion of the product is agglomerated during the calcination stage. The $\mathrm{X}$ ray diffraction pattern of $\mathrm{ZrO}_{2}$ microparticles is shown in Fig. 6. When compared with the JCPDS card (17-923), the tetragonal $\mathrm{ZrO}_{2}$ is identified.

\subsubsection{Effect of $\mathrm{Zr}^{2+}$ concentration}

When the concentration of aqueous zirconium oxyacetate solution varies from 0.5 to $3 \mathrm{M}$, differences in the particle size and the degree of agglomeration have been observed. As shown in 


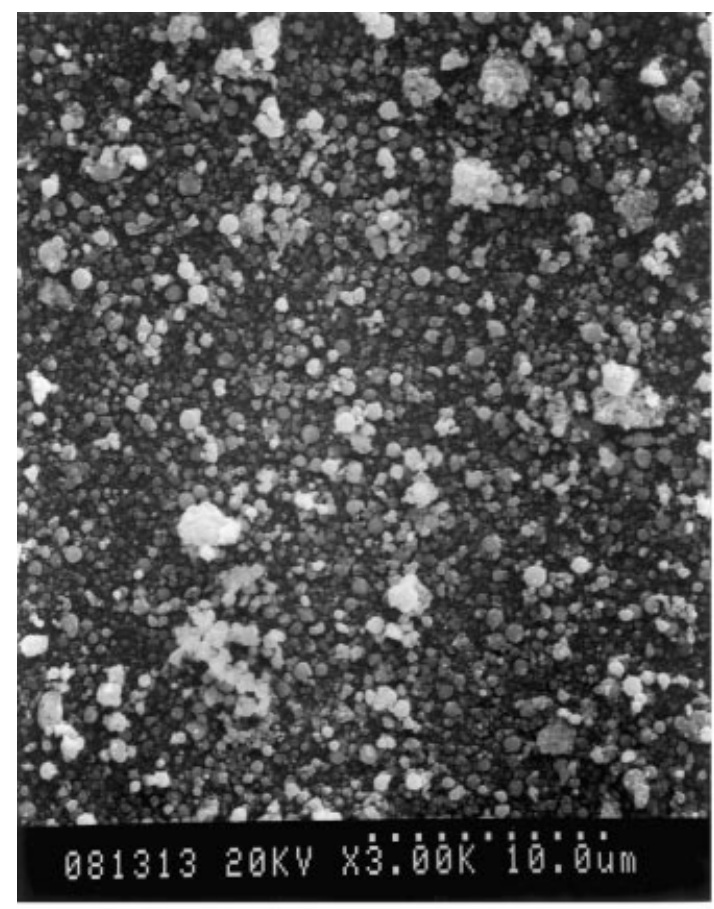

(a)

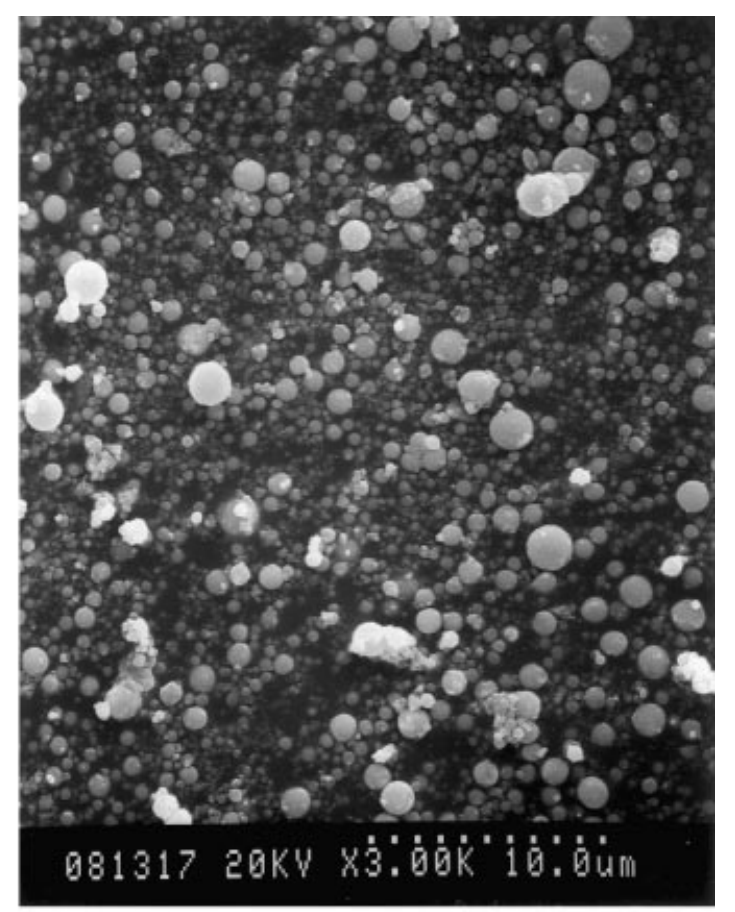

(b)

Fig. 12. Scanning electron micrographs of $\mathrm{ZrO}_{2}$ powder for various concentration of aqueous $\mathrm{ZrO}\left(\mathrm{C}_{2} \mathrm{H}_{3} \mathrm{O}_{2}\right)_{2}$ (a) $2 \mathrm{M}$, (b) $3 \mathrm{M}$. The operating conditions are the same as those in Fig. 11.

Fig. 7, the particle size is larger, the particle size distribution is wider, and the degree of agglomeration is less when the concentration of zirconium oxyacetate becomes higher, but there is almost no difference in particle size when the $\mathrm{Zr}^{2+}$ concentration is between 0.5 and $1 \mathrm{M}$ [compare Figs 5(b) with 7(a) and (b)]. The scanning electron micrographs of $\mathrm{ZrO}_{2}$ powder show that the particles surface are smooth and the morphology of $\mathrm{ZrO}_{2}$ powder is spherical for all $\mathrm{Zr}^{2+}$ concentrations. Besides, the specific surface area of $\mathrm{ZrO}_{2}$ powder decreases from 12.7 to $5.2 \mathrm{~m}^{2} \mathrm{~g}^{-1}$ when the concentrations of $\mathrm{ZrO}\left(\mathrm{C}_{2} \mathrm{H}_{3} \mathrm{O}_{2}\right)_{2}$ increases from 0.5 to $3 \mathrm{M}$. These results reveal that the $\mathrm{ZrO}_{2}$ particles are dense and solid spheres. Figure 8 shows the particle size distribution of $\mathrm{ZrO}_{2}$ powder obtained at various $\mathrm{Zr}^{2+}$ concentrations. Comparing Figs 8 with 4 , we observed that the sizes of $\mathrm{ZrO}_{2}$ particles are larger than the size of waterphase droplets and the size distribution of $\mathrm{ZrO}_{2}$ powder is wider than the size distribution of waterphase droplets in the same experimental run. It is possible that some of the $\mathrm{ZrO}_{2}$ particles are formed due to the coalescence of reverse micelles as illustrated in Fig. 1, and there are more than two droplets involved in the coalescence.

\subsubsection{Effect of ammonia concentration}

When the ammonia concentration of water-phase ranges from 4 to $14 \mathrm{M}$, the reverse emulsions are stable and the $\mathrm{ZrO}_{2}$ powder are produced with spherical morphology at all ammonia concentrations. It has a minor effect on the particle size and shape of the product. When the ammonia concentration is $14 \mathrm{M}$, the particle size is slightly smaller when compared with the ammonia concentration of $4 \mathrm{M}$.

\subsubsection{Effect of $w / o$ volume ratio}

The w/o volume ratio affects the emulsion stability. Various ratios were tested in this experiment. When the volume ratio is $2 / 100$ or $5 / 100$, the emulsion is very unstable and the produced $\mathrm{ZrO}_{2}$ particles appear irregular as shown in Fig. 9 for w/ o volume ratio $=5 / 100$. This is an expected result because at high w/o ratio the chemical reaction takes place in the bulk instead of the droplets at low w/o ratio, which gives spherical and small particles with a narrow size distribution.

\subsubsection{Effect of surfactant weight}

The amount of surfactant Span 80 added to the system has a significant effect on the characteristics of emulsion and thus on the characterization of particles. Varying the weight of Span 80 from 0.8 to $1.6 \mathrm{~g}$, the emulsion solutions are stable for $12 \mathrm{~h}$. The precursors and $\mathrm{ZrO}_{2}$ particles with spherical morphology and few agglomerates are obtained, when the weight of Span 80 added is between 1.0 and $1.2 \mathrm{~g}$. Experimental results reported by Akinc and Richardson ${ }^{8}$ show that higher concentrations of surfactant produces smaller droplet size and thus smaller particles. However, when the amount of Span 80 added is more than $1.5 \mathrm{~g}$, the produced $\mathrm{ZrO}_{2}$ particles appear more agglomerates, presuming 
that the large amount of surfactant is difficult to remove during washing.

\subsubsection{Effect of mixing intensity and time during the emulsion formation}

In the previous experiments, the emulsion solutions were prepared using the standard horn at $165 \mathrm{~W}$. It is interesting to see the effect of the mixing intensity on the characteristics of emulsion and particles. Using the high intensity horn at $220 \mathrm{~W}$, the emulsions are unstable at low concentration between 0.5 and $1.5 \mathrm{M}$ when the mixing time and the volume ratio of $\mathrm{w} / \mathrm{o}$ are kept at $3 \mathrm{~min}$ and $1 /$ 100 , respectively. If the concentration of zirconium oxyacetate is between 2 and $3 \mathrm{M}$, the reverse emulsion solutions become stable. The size distribution of the water-phase droplets and $\mathrm{ZrO}_{2}$ powder are shown in Figs 10 and 11, respectively, for the concentration of $\mathrm{Zr}^{2+}$ solution being 2 and $3 \mathrm{M}$. The results are similar to that obtained by using the

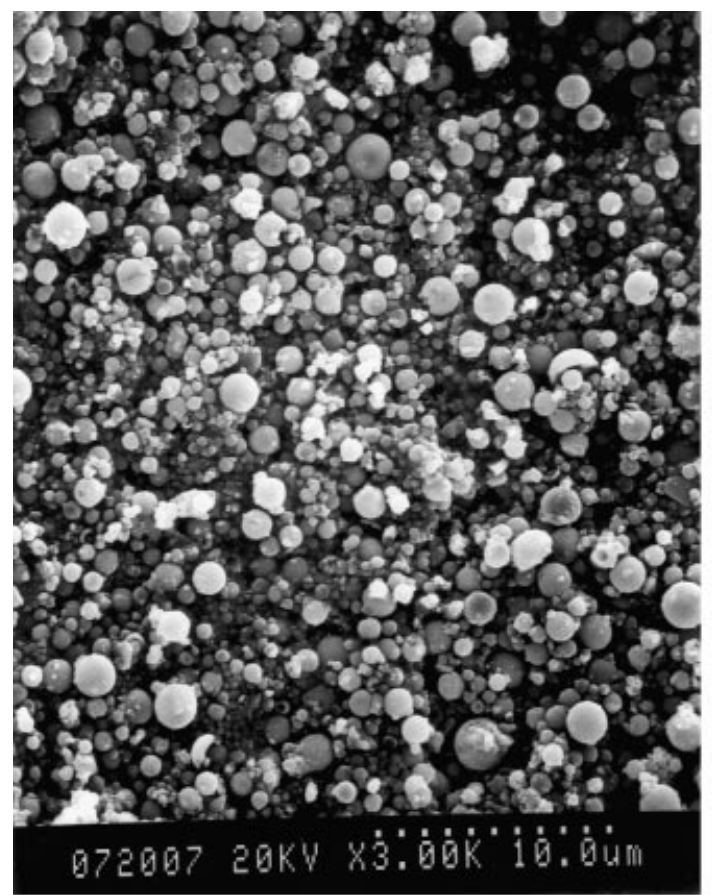

(a)

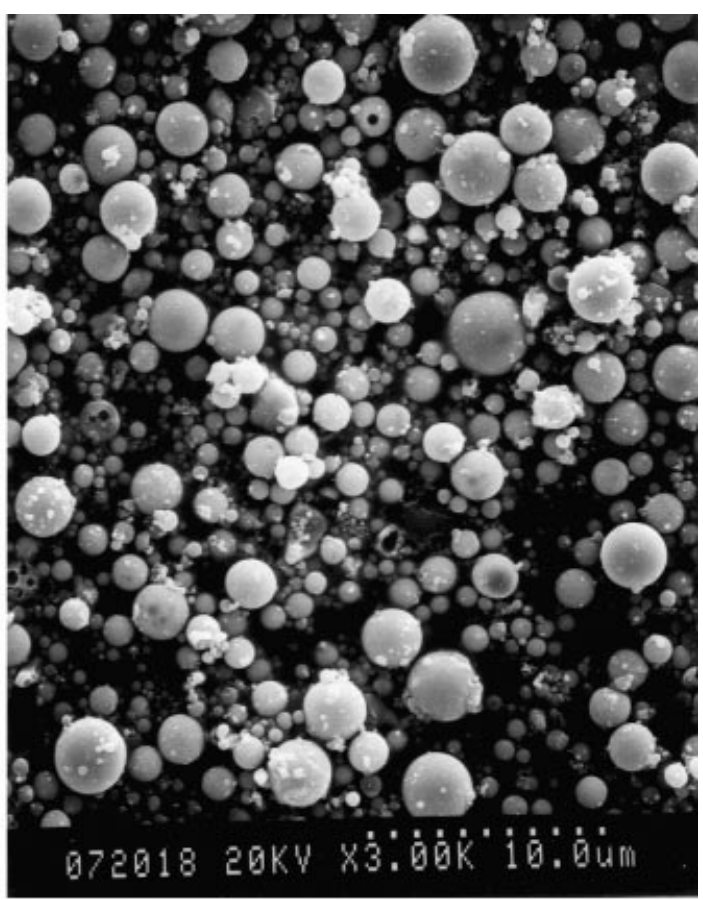

(b)

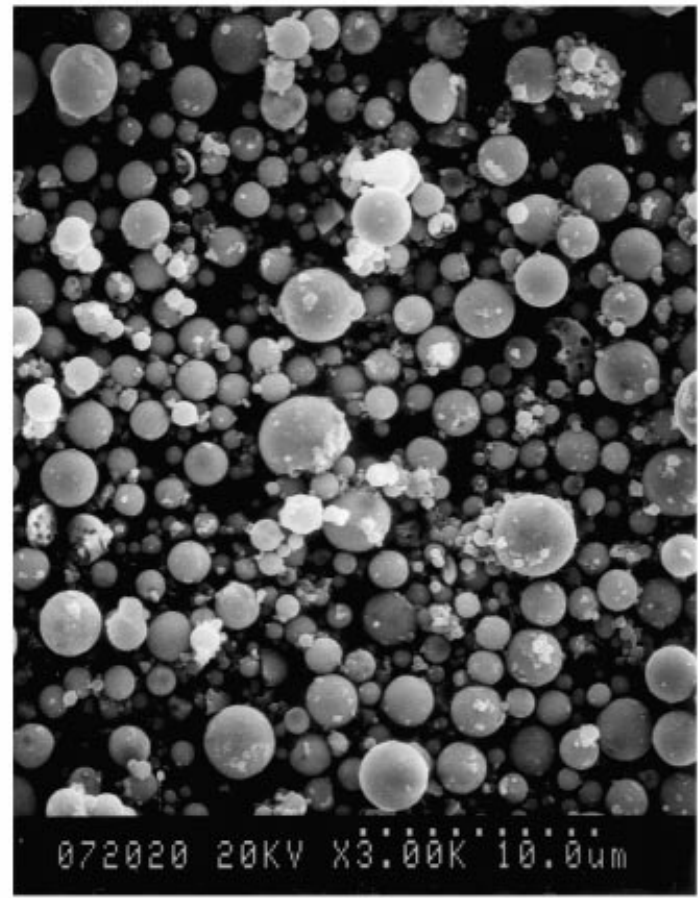

(c)

Fig. 13. Scanning electron micrographs of $\mathrm{ZrO}_{2}$ powder for the $\mathrm{w} / \mathrm{o}$ volume ratio $1 / 100$ by using Span 40 as the surfactant showing the effect of $\mathrm{ZrO}\left(\mathrm{C}_{2} \mathrm{H}_{3} \mathrm{O}_{2}\right)_{2}$ concentration (a) $1 \mathrm{M}$, (b) $2 \mathrm{M}$, (c) $3 \mathrm{M}$. The other operation conditions are the same as those in Table 2 . 
standard horn of low intensity; the size distribution of water-phase droplets is narrow and shifts to larger size at high $\mathrm{Zr}^{2+}$ concentration (see Fig. 4) and the size distribution of $\mathrm{ZrO}_{2}$ particles is wider than that of water-phase droplets (see Fig. 8). However, the average sizes of the water-phase droplets and $\mathrm{ZrO}_{2}$ particles obtained by using the high intensity are smaller than that obtained by using the low intensity horn (comparing Figs 4 with 10 and 8 with 11). Figure 12 shows the SEM micrographs of the produced $\mathrm{ZrO}_{2}$ microparticles, which are spherical in shape and larger at higher $\mathrm{Zr}^{2+}$ concentration. The results on morphology are similar to that by using the low intensity horn.

The mixing time during emulsion formation also affects the characteristics of emulsion is. Using the power of standard tapped horn with $165 \mathrm{~W}$, the mixing time is varied from $3 \mathrm{~min}$ to $30 \mathrm{~min}$ when the concentration of $\mathrm{Zr}^{2+}$ solution is kept $1 \mathrm{M}$. If the mixing time during emulsion formation is more than $3 \mathrm{~min}$, the emulsion solutions are unstable and the produced $\mathrm{ZrO}_{2}$ particles appear irregular. When the mixing time during emulsion formation is $3 \mathrm{~min}$, the spherical $\mathrm{ZrO}_{2}$ microparticles are produced.

\subsection{Comparison of experimental results of different surfactants}

Span 40 produces more stable emulsions than Span 80 as far as the volume ratio of $\mathrm{w} / \mathrm{o}$ is concerned (see Table 2). Therefore, experiments are performed to compare the results of the two surfactants, especially on the effect of $\mathrm{Zr}^{2+}$ concentration. While keeping the weight of Span $40(1.2 \mathrm{~g})$ and volume ration of w/o (1/100) constant, differences in the particles size and degree of agglomeration have

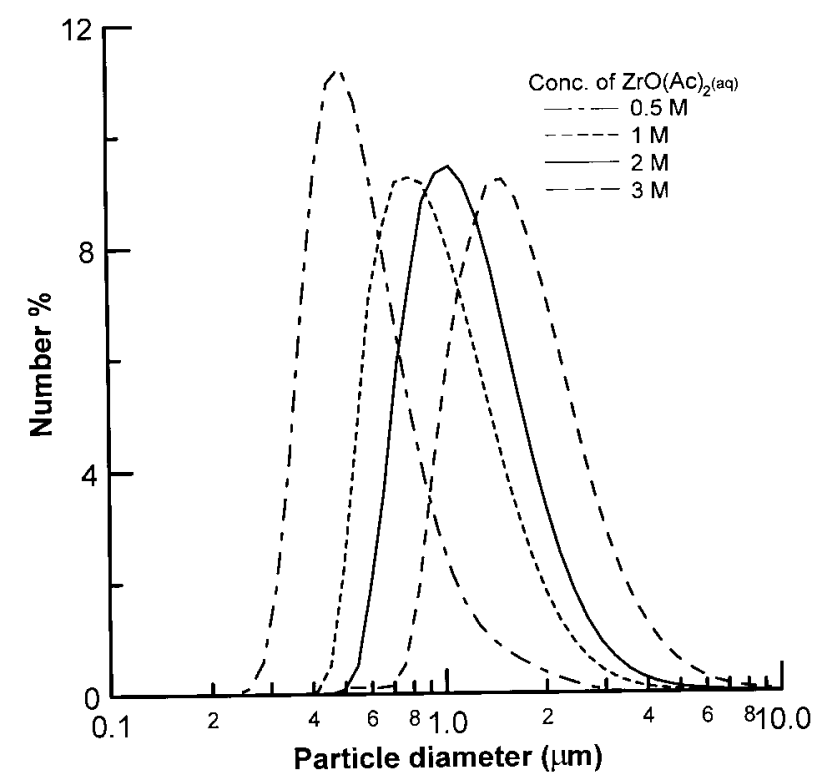

Fig. 14. Effect of $\mathrm{ZrO}\left(\mathrm{C}_{2} \mathrm{H}_{3} \mathrm{O}_{2}\right)_{2}$ concentration on the particle size distribution the $\mathrm{ZrO}_{2}$ when the w/o volume ratio is kept 1/ 100 using Span 40 as the surfactant. The other operation conditions are the same as those in Table 2. been observed at various $\mathrm{Zr}^{2+}$ concentration. As shown in Fig. 13, the particle size is larger, the particle size distribution is wider, and the degree of agglomeration is less when the concentration of zirconium oxyacetate becomes higher. Similar results have been obtained for Span 80 as the surfactant. Figure 14 shows the size distribution of $\mathrm{ZrO}_{2}$ product obtained at various $\mathrm{Zr}^{2+}$ concentrations using Span 40 as the surfactant. The particle size is from a few-hundred nanometers to micrometers. The average particles size of $\mathrm{ZrO}_{2}$ for Span 40 is slightly larger than that for Span 80 .

\section{Conclusions}

The $\mathrm{ZrO}_{2}$ microparticles with spherical morphology are successfully prepared by the precipitation process which is caused by the contact between two emulsion solutions. In the method, two solutions of w/o emulsion, using aqueous ammonia and zirconium oxyacetate as the water phases and heptane as the oil phase, are prepared and mixed to form $\mathrm{ZrO}_{2}$ particles. Factors that affect the size and shape of the product are investigated. The influence of surfactant type (HLB value) on the emulsion stability is drastic. The stability of emulsion significantly affects the morphology of the obtained $\mathrm{ZrO}_{2}$ powder. When the concentration of zirconium oxyacetate ranges from 0.5 to $3 \mathrm{M}$ using Span 40 or Span 80 as the surfactant, the emulsions are stable and spherical $\mathrm{ZrO}_{2}$ microparticles are produced. When the $\mathrm{Zr}^{2+}$ concentration becomes higher, the particle size is larger, the particle size distribution is wider, and the degree of agglomeration is less regardless the surfactant type. A comparison of the experimental results of Span 40 and Span 80 indicates that the particle size distribution curves shift to larger sizes for all $\mathrm{Zr}^{2+}$ concentrations when Span 40 used as the surfactant. The size of the produced particles are from several hundred nanometers to micrometers depending on the surfactant type, mixing intensity and time, and compositions of emulsion.

\section{Acknowledgements}

This study is supported by National Science Council, R.O.C., under Contract NSC 87-2214-E002-032. Thanks for the help of Ching-Yen Lin and Chin-Yuan Tang in Advanced Instrumentation Center, National Taiwan University.

\section{References}

1. M, Li. and Messing, G. L., Preparation of spherical zirconia particles by controlled coagulation in zirconia sols. In Ceramic Powder Science III, Ceramic Transactions, 
Vol. 12, ed. G. L. Messing, E. R. Fuller, Jr and H. Hausner. The American Ceramic Society, Westerville, $\mathrm{OH}$, 1990, pp. 129-136.

2. Rinn, G. and Schmidt, H. Preparation of monodispersed zirconia powders from solution. In Ceramic Powder Science II: A, Ceramic Transactions, Vol. 1, ed. G. L. Messing, E. R. Fuller, Jr and H. Hausner. The American Ceramic Society, Westerville, OH, 1987, pp. 23-30.

3. Zhang, S. C. and Messing, G. L. Solid particle formation during spray pyrolysis. In Ceramic Powder Science III, Ceramic Transactions, Vol. 12, ed. G. L. Messing, E. R. Fuller Jr and H. Hausner. The American Ceramic Society, Westerville, OH, 1990, pp. 49-52.

4. Maher, G. H., Hutchins, C. E. and Ross, S. D., Preparation and characterization of ceramic fine powders produced by the emulsion process. Am. Ceram. Soc. Bull., 1993, 72(5), 72-76.

5. Maher, G. H., Hutchins, C. E. and Ross, S. D., Preparation and characterization of ceramic fine powders produced by the emulsion process. J. Mat. Proc. Tech, 1996, 56, 200210 .

6. Celikkaya, A. and Akinc, M., Synthesis and characterization of yttria powders by emulsion precipitation. In Ceramic Powder Science II: A, Ceramic Transactions, Vol. 1, ed. G. L. Messing, E. R. Fuller, Jr and H. Hausner. The American Ceramic Society, Westerville, OH, 1987, pp. 110-118.

7. Akinc, M. and Celikkaya, A., Preparation of yttria powders by emulsion precipitation, In Advances in Ceramics, Vol. 21, ed. G. L. Messing, K. S. Mazdiyasni, J. W. McCauley and R. A. Haber. The American Ceramic Society, Westerville, OH, 1987, pp. 57-67.
8. Akinc, M. and Richardson, K., Preparation of ceramic powders from emulsion. Mat. Res. Soc. Symp. Proc., 1986, 73, 99-109.

9. Richardson, K. and Akinc, M., Preparation of spherical yttrium oxide powders using emulsion evaporation. Ceram. Int., 1987, 13, 253-261.

10. Sarikays, Y. and Akine, M., Preparation of alumina microshells by the emulsion evaporation technique. Ceram. Int., 1988, 14, 239-244.

11. Bauer, W. and Tomandl, G., Preparation of spherical $\mathrm{TiO}_{2}$ particles by an emulsion method using $\mathrm{TiCl}_{4}$. Ceram. Int., 1994, 20, 189-193.

12. Shyu, L. J. and Cambria, F. M., Emulsion precipitation and characterization of zirconia. Mat. Res. Soc. Symp. Proc., 1990, 180, 837-841.

13. Kanai, T., Rhine, W. E. and Bowen, H. K., Preparation of $2 \mathrm{ZrO}_{2} \cdot \mathrm{Yb}_{2} \mathrm{O}_{3}$ by emulsion techniques. In Ceramic Powder Science II: A, Ceramic Transactions, Vol. 1, ed. G. L. Messing, E. R. Fuller Jr and H. Hausner. The American Ceramic Society, Westerville, OH, 1987, pp. 119-126.

14. Sangeeta, D. R., Zhengkui, X. and David, A. P., Nanometer-sized $\mathrm{ZrO}_{2}$ particles prepared by a sol-emulsiongel method. J. Am. Ceram. Soc., 1990, 73, 2760-2763.

15. Gao, L., Qiao, H. C. and Yan, D. S., Preparation of ultrafine zirconia powder by emulsion method. J. Eur. Ceram. Soc., 1996, 16, 437-440.

16. Prince, L. M., Microemulsions Theory and Practice, Academic Press, New York, 1977, p. 38.

17. Lissant, K. J., Emulsions and Emulsion Technology. Marcel Dekker, New York, 1974, p. 189. 